\title{
Spacetime the one substance
}

\author{
Jonathan Schaffer
}

Published online: 1 April 2009

(C) Springer Science+Business Media B.V. 2009

\begin{abstract}
What is the relation between material objects and spacetime regions? Supposing that spacetime regions are one sort of substance, there remains the question of whether or not material objects are a second sort of substance. This is the question of dualistic versus monistic substantivalism. I will defend the monistic view. In particular, I will maintain that material objects should be identified with spacetime regions. There is the spacetime manifold, and the fundamental properties are pinned directly to it.
\end{abstract}

Keywords Spacetime $\cdot$ Substantivalism $\cdot$ Supersubstantivalism $\cdot$ Monism

"Space and Time, so far from being the least self-subsistent of things, are in truth in their indissoluble union the ultimate reality in its simplest and barest terms;..."

(Alexander 1950, p. 233)

\section{Substantivalisms, dualistic and monistic}

What is the relation between material objects and spacetime regions? I will be presupposing that spacetime regions are one sort of substance, and posing the question of whether to think of material objects as a second sort of substance. But first I should clarify the presupposition and the question.

What I am presupposing is that spacetime regions are one sort of substance, where a substance is a fundamental entity. A fundamental entity is basic, ultimate, and irreducible. It is not dependent on, grounded in, or derivative from anything

J. Schaffer (ه)

Philosophy RSSS, Australian National University, Canberra, ACT 0200, Australia

e-mail: jonathan.schaffer@anu.edu.au 
else. ${ }^{1}$ Call this view of spacetime substantivalism. According to substantivalism, the fundamental spacetime regions are not derivative from distance relations between material objects, as the relationalist maintains. Nor are they dependent on anything deeper, as other forms of anti-substantivalism maintain. Thus spacetime is not, as Newton maintained, "an emanative effect of God and an affection of every kind of being” (2004, p. 21). ${ }^{2}$

I should clarify four points about substantivalism. First, substantivalism says nothing about material objects. It only says that spacetime regions are one sort of substance. Whether material objects are a second sort of substance is a further question. Indeed it is the central question of what follows.

Second, substantivalism says nothing about the structure of spacetime. It says nothing about points, manifolds, or metrics. For instance, it is neutral as to whether general relativistic spacetime should be identified with the manifold M (Earman 1989; Norton 2004), or with M plus the metric field g (Maudlin 1993; Hoefer 1996).

Third, substantivalism says nothing about whether the fundamental spatiotemporal regions are unextended points, mid-sized regions, or the entire manifold as a whole. It is thus neutral as to whether (i) spacetime as a whole is a single substance, with points individuated by their place within the whole, as per moderate structural realism (Esfeld and Lam 2008) ${ }^{3}$; or (ii) whether spacetime is a collection of many independent substances. (I will be arguing that the best form of substantivalism treats the whole of spacetime as a single substance: $\S 2$. But that is not built into the characterization of substantivalism itself.)

Fourth and finally, substantivalism is the consensus view among philosophers of physics, for reasons that Earman summarizes:

The absolutist can point to three reasons for accepting a substratum of spacetime points: the need to support the structures that define absolute motion, the need to support fields, and the need to ground the right/left distinction when parity conservation fails $\left(1989\right.$, p. 173). ${ }^{4}$

\footnotetext{
${ }^{1}$ Such a notion of substance traces back to Aristotle (1971, p. 5). As Descartes puts it: "By substance, we can understand nothing other than a thing which exists in such a way as to depend on no other thing for its existence" (Descartes 1985, p. 210; c.f. Spinoza 1985, p. 408).

2 Newton is often cast as the arch-substantivalist, but I think that such casting is historically incorrect. Newton explicitly says that space "fits neither substances nor accidents," not being a substance because it is "not absolute in itself" (Newton 2004, p. 21). When Newton characterizes space as "an affection of every kind of being" (2004, p. 21), he is presumably characterizing space as belonging to Aristotle's category of affection, for which Aristotle gives the examples "being cut" and "being burned" (Aristotle 1971 , p. 4). So for Newton, "being placed" is what happens to something when it comes to be, and space is the totality of such results.

3 Thus Esfeld and Lam say that in spatiotemporal structure "we get the relata and the relations at once as the internal structure of a whole" (Esfeld and Lam 2008, p. 34), and characterize their view as substantivalist - neutral between dualistic ('Newtonian') and monistic ('Cartesian-Spinozean') substantivalism, but opposed to ('Leibnizean') relationalism (Esfeld and Lam 2008, pp. 42-43).

4 Though see Barbour 2000 for a recent defense of relationalism. Also see Maudlin (Maudlin 2007, pp. 87-89) for a reply to Barbour which brings out a fourth motivation for substantivalism, namely being able to define distance via length of spatiotemporal path (metrical constraints like the triangle inequality follow from this definition, whereas on Barbour's approach such constraints must be stipulated independently).
} 
So I suspect that substantivalism is true. Only I will not be arguing for this here. Rather I will be focusing on a question arising for substantivalism, as to whether or not material objects are a second sort of substance. Even the committed relationalist should be interested in this question, if only to know her enemy.

So onto the question: given that spacetime is one sort of substance, should material objects be regarded as a second distinct sort of substance? Yes, says the dualistic substantivalist. On the dualistic picture, spacetime is the container and material objects are the contained. There is also a fundamental relation of containment which links the container to what it contains. When God makes the world, she must create the receptacle, and fill it with material. Then she can pin the fundamental properties onto the material substrata that fill the receptacle.

No, says the monistic substantivalist. Spacetime is substance enough. There is no need for the dualism of the contained and the contained (or for fundamental containment relations). When God makes the world, she need only create spacetime. Then she can pin the fundamental properties directly to spacetime. ${ }^{5}$

Dualistic substantivalism is by far the more natural and popular view. The dualistic ontology of container and contained can claim a pedigree tracing back to Plato's Timaeus (Zeyl 2005, §6). The dualistic ontology remains mainstream today. To take just one illustration, Hudson's book length treatment of space begins by explicitly presupposing a dualistic "occupancy account" (Hudson 2006, pp. 2-3).

Monistic substantivalism, by contrast, is a revisionary and unpopular view. Though it has had its advocates, including Descartes, Spinoza, and Alexander. As Descartes says:

There is no real distinction between space, or internal place [the space occupied by a body], and the corporeal substance contained in it; the only difference lies in the way in which we are accustomed to conceive of them (1985, p. 227).

More recent monists include Quine (1981, p. 17), Field (1984, p. 75), Lewis (1986, p. 76), Sider (2001, p. 110), and Skow (2005). Though only Skow offers any extended discussion.

It is worth making some distinctions before going further. Monistic substantivalism may be subdivided along three independent dimensions. The first dimension concerns the status accorded material objects. I will defend the identity view, which identifies material objects with spacetime regions. I believe this to be the view of Descartes and the other advocates of monistic substantivalism above.

But the monist need not hold the identity view. She might hold the eliminative view, which denies the existence of material objects altogether. I consider this view extremely radical. As I will argue below (\$3), spacetime regions can play the main role of material objects, in serving as the pincushions for properties. So I consider

\footnotetext{
5 Terminology: monistic substantivalism is also known as "super-substantivalism" (Sklar 1974) and as "Cartesian-Spinozean substantivalism" (Esfeld and Lam 2008, p. 42), inter alia. My usage of "monism" and "dualism" is analogous to the usage in philosophy of mind as to whether mind and body are one sort of substance or two. Monistic substantivalism is not the same view as the doctrine I elsewhere call "priority monism"- though I will be arguing that the two doctrines are connected $(\S 2)$.
} 
the eliminative view to be unwarranted. In any case I will not discuss the eliminative view any further in what follows.

The monist might also hold the constitution view, which accepts the existence of material objects and does not identify them with spacetime regions, but rather takes material objects to be constituted by - and in that sense derivative from-spacetime regions. The constitution view may be understood as identifying spacetime regions with matter, while regarding material objects as constituted by, but not identical with, their matter. I am skeptical of the very idea of constitution without identity. So I consider the constitution view to be built on shaky foundations. But I recognize that this is a controversial matter, and accordingly will keep the constitution view under discussion alongside the identity view.

A second dimension along which monistic substantivalism may be subdivided concerns the restrictions imposed on the fundamental properties. To illustrate, the monist may allow any property whatsoever to be fundamental, or she may restrict the fundamental properties to the intrinsic properties, or she may even restrict the fundamental properties to the geometric properties. Obviously many more positions are possible. I prefer the intrinsic property view, but nothing in what follows will turn on this dimension of classification. That said, it is important to appreciate that monistic substantivalism is not committed to the geometric property view. ${ }^{6}$

A third dimension of subdivision concerns the restrictions imposed on the spacetime regions that get identified with material objects (or that get identified with constituting matter). To illustrate, the monist may identify every spacetime region with a material object, or she may identify every maximally connected spacetime region with a material object, or she may identify every spacetime region full of non-zero mass-energy with a material object. Obviously many more positions are possible. I prefer the unrestricted view, and this will play a minor role in one of the objections to monism ( $\$ 4)$.

I will use the following terminology to distinguish versions of monistic substantivalism. The identity view - which is the view that I will defend-identifies every spacetime region with a material object. The restricted identity view identifies spacetime regions meeting some further condition (such as maximal connectedness) with material objects, where this condition is discriminating, in holding of some but not all regions. The constitution view takes every spacetime region to constitute a material object. And the restricted constitution view takes spacetime regions meeting some further discriminating condition to constitute material objects.

Putting this together I am presupposing that spacetime regions are one sort of substance. I am asking whether or not material objects should be thought of as a second sort of substance. I will be defending the monistic view. In particular I will be defending the identity view, which is the version of monism that identifies every spacetime region with a material object. On this view there is no distinction between the container and the contained.

\footnotetext{
6 The geometric property view guided the program of geometrodynamics in physics (Wheeler 1962). Geometrodynamics is now widely acknowledged to be empirically inadequate.
} 


\section{The identity view packaged}

I will begin by clarifying three controversial though defensible consequences of the identity view, which is the version of monistic substantivalism that identifies every spacetime region with a material object. This is to trace some of the conceptual interconnections between the identity view and a wider range of metaphysical views. Whether these interconnections count for or against the identity view will be left to the judgment of the reader.

The first consequence of the identity view is four-dimensionalism for material objects. The major linking premise is four-dimensionalism about spacetime regions:

1. Spacetime regions perdure.

In other words, spacetime regions stretch temporally in the same way they stretch spatially. They do not endure but perdure (Sider 2001, p. 110). Given fourdimensionalism about spacetime regions as per 1, and the monistic identification of material objects with spacetime regions, four-dimensionalism about material objects follows immediately.

The second consequence is unrestricted composition and decomposition for material objects. The major linking premise is unrestricted composition and decomposition for spacetime regions:

2. Spacetime regions satisfy unrestricted composition and decomposition.

In other words (i) for any plurality of spacetime regions, there is a region that fuses them. Gerrymandered and discontinuous regions are regions all the same. Also (ii) for any extended spacetime region, there are sub-regions that fission it. Arbitrary undetached regions are regions all the same. ${ }^{7}$ Given unrestricted composition and decomposition for spacetime regions as per 2, and the monistic identification of material objects with spacetime regions, unrestricted composition and decomposition for material objects follows immediately.

The third consequence is priority monism, in the sense of the holistic doctrine that the whole material cosmos is ontologically prior to any of its parts (Schaffer 2007, forthcoming). The major linking premise is that the whole spatiotemporal manifold is prior to any of its proper sub-regions:

3. The whole spatiotemporal manifold is prior to any of its proper sub-regions.

There are two reasons to endorse 3. First, topological notions such as disconnectedness (where a region is connected if and only if it is not the union of any two nonnull separated regions), and geometrical notions such as distance (understood via the length of the shortest path between two points), make implicit reference to the whole manifold. Bricker provides the following elegant example:

\footnotetext{
7 Thus van Inwagen's (dualistic) formulation of the doctrine of arbitrary undetached parts runs as follows: "For every material object $\mathrm{M}$, if $\mathrm{R}$ is the region of space occupied by $\mathrm{M}$ at time $t$, and if sub-R is any occupiable sub-region of $\mathrm{R}$ whatever, there exists a material object that occupies the region sub- $\mathrm{R}$ at $t$ " (van Inwagen 1981, p. 123). Here it is presupposed that arbitrary sub-regions exist, and only questioned as to whether they always contain material objects.
} 
Manifold structure is in part topological structure, and topological structure, it is easy to see, is irreducibly global. Consider a two-dimensional Euclidean plane (and the surface of) an infinite cylinder. They are locally indistinguishable: each consists of continuum-many points that are locally Euclidean. But the plane and the cylinder differ topologically. For example, the plane, but not the cylinder, is simply connected: all closed paths can be continually contracted to a point $(1993$, p. 288$){ }^{8}$

To be a part of spacetime is to have such topological and geometrical features, and parts of spacetime have these constitutive features in virtue of their embedding in the whole. The parts thus depend for their natures on the whole.

A second reason to endorse 3 is that —at least on metric essentialist and moderate structural realist views - the parts of spacetime are individuated by their place in the whole. As Newton himself maintained:

[I]f yesterday could change places with today... [yesterday] would lose its individuality and would no longer be yesterday, but today; [likewise] the parts of space are individuated by their positions, so that if any two could change their positions, they would change their individuality at the same time and each would be converted numerically into the other. The parts of duration and space are understood to be the same as they really are only because of their mutual order and position;... (2004, p. 25; c.f. Maudlin 1989; Esfeld and Lam 2008, p. 37)

Thus the parts of spacetime exist as individuals in virtue of their position within the whole. The parts thus depend for their identities on the whole.

Given the priority of the whole for spacetime, and the monistic identification of material objects with spacetime regions, the priority of the whole for material objects follows immediately. And so, as Alexander puts it, "Space-Time takes for us the place of what is called the Absolute in idealistic systems" (1950, p. 346). ${ }^{9}$

Four dimensionalism, unrestricted composition and decomposition, and priority monism are all controversial but defensible views (Sider 2001; Schaffer forthcoming). I cannot engage in these controversies here. If you like some of these views, you might like the identity version of monistic substantivalism for cohering with them. Conversely, if you dislike some of these views, you might dislike the identity

\footnotetext{
${ }^{8}$ Handedness is another holistic feature. Whether a right-handed and left-handed glove can be superimposed by rigid motion depends, as Nerlich notes, "on the dimensionality or the orientability, but in any case on some aspect of the overall connectedness or topology of the space" (1994, p. 53).

${ }^{9}$ Historically, the priority of the whole of space to its parts was affirmed by Descartes (c.f. Carriero 2002, p. 53), Spinoza (c.f. Bennett 1984, p. 86), Leibniz (c.f. Adams 1994, pp. 232-234; Earman 1989, p. 16), and Kant, inter alia. For instance, Kant spoke of space as "essentially one," arguing that "these parts cannot precede the one all-embracing space, as being, as it were, constituents out of which it can be composed; on the contrary, they can be thought only as in it." (1965, p. 69). Indeed, Kant explicitly maintained that if space and time were not ideal but real, then Spinozistic monism would follow immediately:
}

[I]f this ideality of time and space is not adopted, nothing remains but Spinozism, in which space and time are essential attributes of the Supreme Being Himself, and the things dependent on Him (ourselves, therefore, included) are not substances, but merely accidents inhering in Him;..." (1996, pp. 124-125). 
version of monistic substantivalism for adhering to them. (Or you might reject some of the connecting theses 1-3.) Given 1-3, we have a package deal.

I should clarify that other versions of monistic substantivalism have other consequences. The restricted identity view entails four-dimensionalism and priority monism (provided that the restriction in play is satisfied by the whole manifold), but does not entail unrestricted composition and decomposition. The constitution view entails unrestricted composition and decomposition, but does not entail fourdimensionalism and priority monism. Presumably the constituted object could have different persistence conditions than its constituting matter. And perhaps the priority ordering over the constituted objects could diverge from the priority ordering over the constituting materials. And finally the restricted constitution view has none of the consequences considered. The philosopher unhappy with the dualistic picture may choose the version of monistic substantivalism that best fits her other commitments.

\section{Seven arguments for the identity view}

I will now offer seven arguments for preferring the identity version of monistic substantivalism to its dualistic rival. I should clarify that these are not arguments for preferring the identity view to all other views. These are not arguments for preferring the identity view to anti-substantivalist views about spacetime. I will continue to treat substantivalism as a presupposition. And these are not arguments for preferring the identity view to other versions of monistic substantivalism. Though I will continue to keep other versions of monistic substantivalism under discussion.

The argument from parsimony: Where the monistic substantivalist of any stripe has one sort of substance (and given priority monism, a single fundamental entity of that sort), the dualistic substantivalist needs two sorts of substances (plus the containment relation to link them). What is the necessity for the dualistic doubling of substance types? ${ }^{10}$

To assess whether there is any necessity for the dualistic distinction between material objects and spacetime regions, one should consider the role that material objects are supposed to play. I take it that the primary role that material objects are supposed to play is the role of substrata. Material objects are supposed to provide the pincushions for the properties. As Descartes claims:

We should notice something very well known by the natural light: nothingness possesses no attributes or qualities. It follows that, whenever we find some attributes or qualities, there is necessarily some thing or substance to be found for them to belong to (1985, p. 196; c.f. Locke 1996, pp. 117-118).

\footnotetext{
${ }^{10}$ The parsimony argument is far and away the most popular in the literature. Thus Quine decries: "a redundant ontology containing both physical objects and place-times" (1981, p. 17), Lewis opposes "the dualist conception as uneconomical" (1986, p. 76), and Sider warns that we should not "gratuitously add a category of entities to our ontology," and adds that given substantivalism "The identification of spatiotemporal objects with the regions is just crying out to be made" (2001, p. 110).
} 
Substantival spacetime regions bear properties. So they do what objects should do. Thus there is no need for a second sort of substance to do what has already been done. Spacetime is pincushion enough to support a propertied world.

It is as if the dualist has not just pins (properties) and pincushions (material objects), but also a sewing table (the spacetime manifold) on which the pincushions sit. But once one has the sewing table, the pincushions seem superfluous. Why not push the pins directly into the table?

The argument from harmony: Material objects have geometrical and mereological properties, as do spacetime regions. The geometrical and mereological properties of the material objects are a perfect mirror of the geometrical and mereological properties of their containing spacetime regions. For instance, my hand is hand-shaped, and part of my body. The spacetime region containing my hand is also hand-shaped, and is part of the region containing my body:

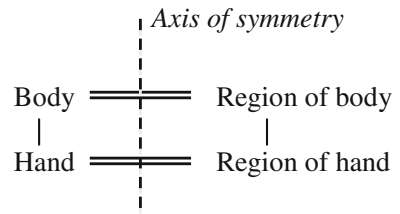

Vertical single line: parthood

Horizontal double line: containment

In general the shape of the contained mirrors the shape of its container, and the parthood relations within the contained mirror the parthood relations within the container.

For the dualist, the geometrical and mereological harmonies between material objects and spacetime regions seem an amazing coincidence. What prevents, for instance, my hand from occupying a region with a different shape? Or what prevents my hand from occupying a region that is not part of the region my body occupies? Indeed, given dualism plus standard recombination principles on fundamental entities, these scenarios should be possible.

For the identity theorist there is no miracle. Material objects just are spacetime regions, so no possibility of disharmony arises. The perfect correlations between the geometrical and mereological properties of the material objects and the spacetime regions containing them are suggestive that at root we are dealing with a single phenomenon. (If you see a face just like your own, consider whether you are looking in a mirror.) The situation is analogous to the situation for substance dualism about the mental. There are remarkable correlations between mental states and brain states, which likewise suggest a single phenomenon at root (Field 1992).

I anticipate two sorts of replies dualists might make to the argument from harmony. The first reply is to deny that material objects have geometrical and mereological properties in themselves. Rather it may be said that only spacetime regions have geometric and mereological properties intrinsically. Material objects only have these properties extrinsically, inheriting them from their containing regions (McDaniel 2004; Hudson 2006, p. 111). ${ }^{11}$

\footnotetext{
11 The dualist could also run the reply in reverse, and say that it is the material objects that have the geometrical and mereological properties intrinsically, and the spacetime regions inherit these properties
} 
The minor trouble with this first reply is that is seems odd to deny that material objects have intrinsic shapes. Descartes, for instance, characterized the material realm (res extensa) as the realm of entities whose primary attribute is extension. In the intrinsicness literature, the shapes of material objects are often taken to be paradigmatic instances of intrinsic properties. Here it is the dualist who holds the revisionary view.

The major trouble with this first reply is that it begins the process of relocating material properties to the spacetime itself. Once one has pinned the geometrical and mereological properties directly onto the receptacle, why stop there? Why not also pin the masses and charges onto the receptacle as well? In general, is there some principled reason for using spacetime as the pincushion for only some of the fundamental properties? The dualist, having doubled the substrata, owes a principled account of how to divide the properties between them.

A second dualistic reply to the argument from harmony would be to trumpet disharmonies as needed to allow for exotic possibilities. Some dualists have claimed that it is possible for there to be exotic possibilities in which the mereological properties of objects fail to match the mereological properties of the regions they occupy. For instance, some dualists have claimed that it is possible for there to be extended simples, which are material objects that have no proper parts, but that occupy spacetime regions that have proper parts.

I think that extended simples are impossible. Or at least, given unrestricted decomposition (part of the package: §2), the impossibility of extended simples is immediate. I grant that extended simples may seem conceivable to those who presuppose dualism. ${ }^{12}$ But the monistic view is that dualism is a conceptual error. It is no objection to an avowedly revisionary proposal that it does not match our current concepts.

But leave extended simples and all the other exotica aside. Presumably there still remains the actual fact of harmony concerning actual hands and bodies, and their containing regions. For the dualist this already seems a miracle. Methodologically, I suggest that one first account for the evident facts, and let the controversial exotica fall where they may.

\footnotetext{
Footnote 11 continued

from the material objects they contain. But this seems to strip the spacetime regions of much of what makes them spatiotemporal. Also, if the dualist wants to speak of unoccupied spacetime regions $(\S 4)$ this will prevent her from assigning geometrical and mereological properties to her unoccupied regions (or else she will need to speak of the material objects that can occupy regions, making the geometry and mereology of regions into a modal property). So it seems best for the dualist to take spacetime regions rather than material objects as having the geometrical and mereological properties intrinsically, though nothing in the main text will turn on this.

12 I take it that the sort of conceivability involved is negative conceivability, in the sense that one can intellectually consider the scenario of there being an extended simple and not find any immediate contradiction lurking. Extended simples are not positively conceivable, in the sense of being visually imaginable. One can try to visually imagine an extended simple sphere, but it will not look any different from an extended composite sphere! In any case the monist will view the conceivability as non-ideal, being based on a conceptual distinction that she thinks should be erased. (See Chalmers 2002 for further discussion of conceivability.).
} 
The first two arguments - the arguments from parsimony and from harmonyare connected. It is the dualist's lack of parsimony that leads her to countenance too many possibilities. It is because the dualist has doubled the substances that she then needs to explain the remarkable correlations between them.

The argument from monopolization: Material objects monopolize the spacetime regions containing them. That is, each spacetime region is exactly occupied by at most one material object. Thus Locke says of bodies that "necessarily each of them exclude any [other bodies] out of the same place" such that "could two bodies be in the same place at the same time; then those two parcels of matter must be one and the same" (1996, p. 134; c.f. Zimmerman 1996; Hudson 2006). Or at least, if one thinks of a table and a chair, and asks if they occupy the same spacetime region, I take it that the obvious answer is no. One does not even need to look.

The dualist has no obvious explanation for monopolization. Why can't her fundamental containment relation hold between the table and spacetime region $r$, and also between the chair and $r$ ? It seems that a brute restriction has to be imposed on containment, to mandate that at most one material object can be contained in each spacetime region.

Alternatively the dualist could attempt a nomological explanation for monopolization. Perhaps monopolization is just a contingent result of our force laws. But monopolization does not seem contingent, in the way that, say, gravitation is. The fact that a dropped chair will fall earthward is a nomological matter, not guaranteed just by the fact that the chair is a material object. But the fact that the chair and table cannot co-locate seems guaranteed simply by the materiality of both objects. (Perhaps the dualist will consider this a conceptual confusion. But then her theory contains revisionary elements as well.)

The identity theorist has an easy explanation for monopolization. For the identity theorist, material objects are spacetime regions. No two distinct regions can exactly occupy one and the same region-if regions $r_{1}$ and $r_{2}$ are at exactly the same region, then $r_{1}=r_{2}$.

I anticipate that the dualist might try to reverse the argument, by pressing for the possibility of co-location. The dualist may bring up imaginary cases involving ghosts walking through walls, sophisticated physical cases such as indiscernible bosons, or contentious metaphysical cases such as statues and lumps. With the imaginary cases of ghosts walking through walls, I submit that such is impossible for material objects. The concept of a ghost involved-one capable of both walking through walls and hurling stones-is an incoherent jumble of immaterial and material features. With the sophisticated physical cases of co-located bosons, I submit that the even more sophisticated treatment of these cases involves field theory. Instead of there being two bosons co-located at region $r$, there is a bosonic field with doubled intensity at $r$. (I will say more about field theory below.)

With the contentious metaphysical cases of constitution, I think that the statue is the lump (constitution is identity). But in any case the philosopher who denies that constitution is identity must explain the remarkable harmonies between the statue and the lump. For instance, both have the same shape and the same mass. The explanation will presumably involve both the statue and the lump having the same matter. But now exactly the same issues will arise with respect to parcels of matter 
monopolizing spacetime regions. For even if material objects like the statue and the lump can co-locate, it certainly seems that parcels of matter cannot co-locate. At this point I think the natural explanation would be to identify matter with spacetime regions. But this is no longer dualistic substantivalism. Material objects are no longer being treated as a second sort of substance, but are instead being treated as dependent on substantival spacetime. Indeed, this is just the view of the monistic substantivalist who holds the constitution view $(\$ 1)$.

But leave ghosts, bosons, and lumps aside. There is still the uncontroversial fact that the table and the chair cannot occupy the same spacetime region, and the dualist is still without an explanation for this evident feature of the world. Methodologically, I again suggest that one first account for the evident facts, and let the controversial cases fall where they may.

The argument from materialization: Material objects cannot exist without occupying spacetime regions. That is, each material object occupies at least one spacetime region. In this vein Hobbes defines "body" as "that, which having no dependence upon our thought, is coincident or coextended with some part of space" (1839, p. 102), and Markosian (2000) argues that what it is to be a material object is to be spatially located. Or at least, if one thinks of the table, and asks whether it could exist without occupying some spacetime region, I take it that the answer is no.

The dualist has no obvious explanation for materialization. Why can't a material object just happen not to stand in the containment relation to any spacetime regions? So it seems that the dualist must impose another brute necessary connection on the world, to require that each material object is contained by at least one spacetime region.

The identity theoretic explanation, in contrast, is immediate. Material objects just are spacetime regions, and so could no more exist without materializing at regions, than could anything exist without itself.

I anticipate that the dualist might consider materialization to be analytic. She might hold that materialization is what makes objects material. On this view objects could fail to materialize, they just would count as immaterial in that case. I reply that the difference between material and immaterial objects is not merely materialization. Material objects have a cluster of other features that immaterial objects do not, such as having mass and charge. Thus consider a particular rock with a certain mass. It is not as if this rock with its mass could exist and have its mass yet fail to materialize (simply being a massive yet immaterial object in that case). Rather the rock with its mass could not fail to materialize, period.

The argument from exhaustion: Material objects are exhausted by their instances. That is, each material object occupies at most one spacetime region. For instance, suppose that this table spends its entire career contained in my office. Then this table cannot also spend its entire career contained in a different office. Multiple location is the prerogative of universals-material objects like tables do not enjoy such liberties (Armstrong 1978).

The dualist has no obvious explanation for exhaustion. Why can't her fundamental containment relation hold between the table and a region $r$ in my office, and also hold between the table and a different region $r^{*}$ of a different office? Indeed, by standard recombination principles on fundamental entities, this scenario 
should be possible. So the dualist seems to need yet another brute restriction on what is possible.

The identity theoretic explanation, in contrast, is immediate. Material objects are spacetime regions, and no one region can be two different regions. By the transitivity of identity, if material object $o$ is identical to spacetime region $r_{1}$, and if $o$ is also identical to region $r_{2}$, then $r_{1}=r_{2}$.

The five arguments given so far are interconnected. Monopolization, materialization, and exhaustion are really just further aspects of the harmony between material objects and spacetime regions-each object gets a region, and no region gets more than one object. All of this harmony is suggestive of a unified phenomenon at root. It is the dualist's lack of parsimony, in doubling the substances, which forces her to impose all manner of brute necessities, so that her two sorts of substances can act as if they were one.

The argument from General Relativity: General Relativistic models are triples $<\mathrm{M}, \mathrm{g}, \mathrm{T}>$ where $\mathrm{M}$ is a four-dimensional continuously differentiable point manifold, $\mathrm{g}$ is a metric-field tensor, and $\mathrm{T}$ is a stress-energy tensor (with both $\mathrm{g}$ and $\mathrm{T}$ defined at every point of $\mathrm{M}$, and with $\mathrm{g}$ and $\mathrm{T}$ coupled by Einstein's field equations). There are no material occupants in $\langle M, g, T\rangle$ triples. That is, the distribution of matter in General Relativity is not given via a list of material objects in occupation relations to regions. Rather the distribution is given by the stressenergy tensor, which is a field, and thus naturally interpreted as a property of the spacetime. As Einstein notes: “[Lorentz's] discovery may be expressed as follows: physical space and the ether are only different terms for the same thing; fields are physical states of space" $\left(1934\right.$, p. 274). ${ }^{13}$

Thus Earman suggests identifying $M$ with the spacetime manifold, and treating $g$ and $\mathrm{T}$ as properties of $\mathrm{M}$ : "Indeed, modern field theory is not implausibly read as saying the physical world is fully described by giving the values of various fields, whether scalar, vector, or tensor, which fields are attributes of the space-time manifold $M$ " (1989, p. 115). ${ }^{14}$ Similarly Norton notes: "a spacetime is a manifold of events with certain fields defined on the manifold. The literal reading is that this manifold is an independently existing structure that bears properties" (2004). ${ }^{15}$

The argument from Quantum Field Theory: Quantum Field Theory, like General Relativity, is a theory of fields (which again are naturally interpreted as states of the spacetime) rather than material occupants. As Weinberg notes, "A quantum field

\footnotetext{
${ }^{13}$ Elsewhere Einstein says: "We may therefore regard matter as being constituted by the regions of space in which the field is extremely intense... There is no place in this new kind of physics for both the field and matter, for the field is the only reality" (quoted in Capek 1961, p. 319).

${ }^{14}$ Elsewhere Earman puts the point as follows: "In a modern, pure field-theoretic physics, $M$ functions as the basic substance, that is, the basic object of predication." (1989, p. 155).

15 There is controversy as to whether the spacetime manifold should be identified with M (Earman 1989, Norton 2004) or with M plus g (Maudlin 1993, Hoefer 1996). The argument of the main text is neutral here, and solely turns on the ontological status of $\mathrm{T}$, which everyone in the debate understands as a feature of the spacetime. As Hoefer notes:
}

Mathematically, the matter field contents could also be thought of as 'properties' of space-time points - a perspective that seems to embody a kind of 'supersubstantivalism,' in that space-time (or its points) are the only real substances in existence. (1996, p. 13). 
theory is a theory in which the fundamental ingredients are fields rather than particles; the particles are little bundles of energy in the field" (1987, pp. 78-79). Thus in quantum field theory, 'particles' turn out to be excitation properties of spacetime itself, as d'Espagnat explains:

Within [quantum field theory] particles are admittedly given the status of mere properties,... But they are properties of something. This something is nothing other than space or space-time, which, being locally structured (variable curvature), have indeed enough 'flexibility' to possess infinitely many 'properties' or particular local configurations (1983, p. 84). ${ }^{16}$

Indeed, there are at least four reasons why quantum field theory is ill-suited to an ontology of material particles: there is the possibility of superposition for the 'bosonic number' operator, the Bose statistics, the Reeh-Schlieder theorem, and Unruh radiation which shows that particle number is not frame invariant (Kuhlmann 2006, p. §5). As Halvorson and Clifton conclude:

Relativistic quantum field theory... does not permit an ontology of localizable particles; and so, strictly speaking, our talk about localizable particles is a fiction. Nonetheless, relativistic quantum field theory does permit talk about particles-albeit, if we understand this talk as really being about the properties of, and interactions among, quantized fields (2002, p. 24).

Thus Redhead claims that particle states "are an idealization," and that quantum field theory "is about fields and their local excitations. That is all there is to it" (1995, p. 135). And Zeh recommends that we "abandon a primordial particle concept entirely, and... replace it with fields only," noting: "this is indeed what has always been done in the formalism of quantum field theory" (2003, p. 330).

The last two arguments reveal how fundamental physics has attained the advantages of the more parsimonious and explanatory monistic framework. Fundamental physics does not need to explain why, for instance, the geometrical properties of material objects are a perfect fit for the geometrical properties of the spacetime regions they occupy, for the equations do not posit anything distinct from regions. On the face-value reading of the equations, there is the spatiotemporal manifold, and the fundamental properties are pinned directly to it. Nothing more. The identity view thus claims the heady virtues of parsimony, explanatoriness, and empirical vindication.

I should note that the restricted identity version of monism can claim all of the advantages of the identity view claimed above. The constitution and restricted constitution versions of monism can claim parsimony, and can claim fit with General Relativity and Quantum Field Theory, insofar as these issues only concern the fundamental ontology. The constitution views preserve the fundamental

16 Here is another passage from d'Espagnat, on the field theoretic basis for 'particles':

In quantum field theory, reality lies at a deeper level than could be imagined by common sense or even by elementary quantum mechanics. A particle is not itself 'a reality'; it is simply a more or less transient property of reality, a level of excitation (to speak as physicists do)... of reality, excited in a fashion corresponding to the field in question. (1983, p. 85). 
ontology of a spacetime bearing fields. But the constitution views may have trouble explaining harmony, monopolization, materialization, and exhaustion. After all, the constituted material object is supposed to have different features from its constituting matter. For instance, the constituted material object is typically allowed to have different de re modal properties than its constituting matter. But given this prospect of different properties, the explanation of the harmonies between material objects and spacetime regions is blocked. Or at least, the constitution theorist owes a principled account of which features of the constituting matter will be preserved in the constituted material object. Only then can the constitution views be assessed with respect to harmony, monopolization, materialization, and exhaustion.

\section{Three arguments for dualistic substantivalism}

It remains to consider three arguments for preferring dualistic substantivalism over the identity version of monistic substantivalism. I should clarify that these are not arguments for preferring dualistic substantivalism to all other views. These are not arguments for preferring dualistic substantivalism to anti-substantivalist views about spacetime. I will continue to treat substantivalism as a presupposition. And these are not arguments for preferring the dualistic view to other versions of monistic substantivalism. Though I will continue to keep other versions of monistic substantivalism under discussion.

The argument from commonsense: Dualistic substantivalism seems to accord better with how we ordinarily speak $(\$ 1)$. We do not normally identify material objects with spacetime regions. Thus Hobbes (critiquing Descartes) writes: "For who knowes not that Extension is one thing and the thing extended another?" (quoted in Malcolm 2002, p. 190). As Sider puts the point: " A region of spacetime bounded out the door and barked at the mailman' - it sure sounds strange to say! Indeed, it sounds like a 'category mistake'” (2001, p. 111; c.f. Skow 2005, p. 6). Indeed the distinction between material objects and spacetime regions is built into ordinary language in the distinction between what and where. The object is what and the region is where, and so it seems that ordinary language does draw a categorical distinction between the container and what it contains.

By way of reply, I agree that commonsense is dualistic. I just don't think commonsense should be taken too serious on this issue. Commonsense-what Einstein called "a deposit of prejudices laid down in the mind before you reach eighteen" (Bell 1951, p. 42) - is a poor guide to the fundamental structure of reality.

An analogy with substance dualism for the mental might be helpful. I think that commonsense embraces substance dualism about the mental. Or at least, many students I have encountered enjoy vague conceptions of an immaterial soul. Supposing so, what does this tell us about the fundamental nature of mental phenomena? Very little, I should think. At most it lends some minor methodological support to dualism about the mental, as the more conservative theory.

The argument from de re modal difference: Material objects and spacetime regions seem - in ordinary thought at least-to differ in de re modal properties. For instance, we would ordinarily grant that the chair might have been located in a 
different place. But we would not ordinarily grant that the place of the chair might have been located in a different place. Chairs can be moved but places cannot. In general, material objects seem to have their locations accidentally, while spacetime regions seem to have their locations essentially.

I would reply by invoking counterpart theory. Consider the standard counterpart theoretic treatment of statues and lumps, on which these are held to be identical, and the seeming difference in their de re modal properties is explained in terms of how different conceptualizations (thinking of it as a statue, versus thinking of it as a lump) make different respects of similarity salient for finding counterparts (Lewis 1971). The same could be said of material objects and spacetime regions (Skow 2005, p. 19). Conceive what is there as filler and its material properties will be most salient for finding counterparts. Conceive what is there as container and its spatiotemporal properties will be most salient for finding counterparts.

The first and second arguments for dualism are connected, insofar as the second argument is a further manifestation of the commonsense object/region division. For this reason I do not think that the second argument should be taken any more seriously than the first. If commonsense does attribute different de re modal properties in a way that conflicts with identity, then the proper conclusion to draw, by my lights, would be that commonsense is wrong about the fundamental structure of reality, and so is attributing different de re modal properties in darkness.

I should note that the constitution version of monism may allow for material objects and spacetime regions to differ in their de re modal properties, just as the statue and lump are allowed to differ in their de re modal properties. Though again I find it difficult to assess the constitution view without a principled account of which features of the constituting matter will be preserved in the constituted material object.

The argument from non-plenitude: It seems that there are (or at least can be) empty regions. That is, it seems that not every spacetime region is occupied by at least one material object. The dualist has an immediate account of what lack of plenitude amounts to. For the dualist, there is an empty region whenever there is a spacetime region that contains no material object. But the identity theorist seems committed to plenitude. For the identity theorist, every region is automatically 'selfoccupied.' So the argument charges the identity theorist with commitment to the Cartesian image of spacetime as a plenum.

I reply that empty regions are impossible in one sense but possible in another. Empty regions are impossible — at least within field theory-in the sense in which an empty region is one that lacks field values. The fundamental fields pervade spacetime. No region escapes. So there is a sense in which field theory vindicates the Cartesian image of the plenum, and the identity theorist is getting this right.

Empty regions are possible in the sense in which an empty region is one with null values for certain fields. For instance, in General Relativity the stress-energy tensor $\mathrm{T}$ is allowed to be null at regions. A given spacetime region may have zero massenergy. So there is a sense in which such a region may rightly be called "empty." What is present may lack certain expected features. As Descartes explains: "In its ordinary use 'empty' usually refers not to a place or space in which there is absolutely nothing at all, but simply to a place in which there is none of the things 
that we think ought to be there" (1985, p. 230). Should a region with zero-mass energy be said to contain no material object, or be considered an empty material object? I see very little at stake in this semantic question, and little harm in saying that a region with zero-mass energy is an empty material object. So I continue to uphold the identity view.

Plenitude would complete a square whose other three legs are monopolization, materialization, and exhaustion (\$3). Materialization and exhaustion together show that every material object occupies one and only one spacetime region, and monopolization and plenitude together show that every spacetime region is occupied by one and only one material object. That yields a one-one mapping between material objects and spacetime regions, which is a perfect opportunity for reduction.

I should note that the restricted identity and restricted constitution versions of monism do not entail plenitude in any sense. They allow that certain regions do not meet the conditions needed for being (or constituting) material objects, and as such are empty regions. For instance, if the monist restricts material objects to those regions of spacetime that are full of non-zero mass-energy, then she will consider a point at which the stress-energy tensor is null to be an empty point in every sense. ${ }^{17}$ She may still claim a one-one mapping between spacetime regions meeting her restrictive conditions, and material objects. So she may still claim a reduction.

What emerges from the arguments considered is that the identity view enjoys the advantages of parsimony, explanatoriness, and empirical vindication, while dualistic substantivalism enjoys the advantage of conservatism. To my mind the balance of considerations clearly favors the identity view. Or at least, I think the balance of considerations clearly favors some version of monistic substantivalism. So I conclude that there is one and only one substance, and that substance is spacetime. To make the world, God only needed to create spacetime, and pin the fundamental fields directly to it. ${ }^{18}$

\section{References}

Adams, R. M. (1994). Leibniz: Determinist theist idealist. New York: Oxford University Press. Alexander, S. (1950). Space, time, and deity: The Gifford lectures at Glasgow 1916-1918, Vol. 1. New York: The Humanities Press.

Aristotle (1971). In J. Barnes (Ed.), The complete works of Aristotle (Vol. 1). Princeton University Press, Princeton.

\footnotetext{
17 In this vein Skow provides the following suggestion on behalf of the monistic substantivalist: "say that material objects differ from other regions of spacetime in their accidental properties-like, for example, mass and charge" (2005, p. 9). Robinson proposes a generalization of this view on which material objects are regions infused with "properties that propagate" (1982, p. 341).

18 Thanks to Phillip Bricker, Hud Hudson, Jim Kreines, Josh Parsons, Louis de Rosset, Denis Robinson, Ted Sider, Brad Skow, and audiences at Mereology, Topology, and Location (Rutgers), the History and Philosophy of Science group at Leeds, the AAP-NZ, the Australian National University, and Virginia Commonwealth University.
} 
Armstrong, D. M. (1978). Nominalism and realism: Universals and scientific realism (Vol. 1). Cambridge: Cambridge University Press.

Barbour, J. (2000). The end of time: The next revolution in physics. Oxford: Oxford University Press.

Bell, E. T. (1951). Mathematics: Queen and servant of science. Mathematical Association of America, New York.

Bennett, J. (1984). A study of spinoza's ethics. Indianapolis: Hackett Publishing Company.

Bricker, P. (1993). The fabric of space: Intrinsic vs. extrinsic distance relations. Midwest Studies in Philosophy, 18, 271-294.

Capek, M. (1961). The philosophical impact of contemporary physics. New York: Van Nostrand Reinhold.

Carriero, J. (2002). Monism in Spinoza. In O. Koistinen \& J. Biro (Eds.), Spinoza: Metaphysical themes (pp. 38-59). Oxford: Oxford University Press.

Chalmers, D. (2002). Does conceivability entail possibility? In T. Szabo Gendler \& J. Hawthorne (Eds.), Conceivability and possibility (pp. 145-200). Oxford: Oxford Univerity Press.

d'Espagnat, B. (1983). In search of reality. New York: Springer-Verlag.

Descartes, R. (1985). The philosophical writings of descartes (Vol. I) (J. Cottingham, R. Stoothoff \& D. Murdoch, Trans.). Cambridge: Cambridge University Press.

Earman, J. (1989). World enough and spacetime. Cambridge: MIT Press.

Einstein, A. (1934). The world as $i$ see it. New York: Covici-Friede Press.

Esfeld, M., \& Lam, V. (2008). Moderate structural realism about space-time. Synthese, 160, 27-46.

Field, H. (1984). Can we dispense with space-time? In PSA 1984 Proceedings of the Biennial Meeting of the Philosophy of Science Association (Vol. 2, pp. 33-90). East Lansing, MI: Philosophy of Science Association.

Field, H. (1992). Physicalism. In J. Earman (Ed.), Inference, explanation and other frustrations: Essays in the philosophy of science (pp. 271-291). Los Angels: University of California Press.

Halvorson, H., \& Clifton, R. (2002). No place for particles in relativistic quantum theories? Philosophy of Science, 69, 1-28.

Hobbes, T. (1839). De Corpore. In W. Molesworth (Ed.), The english works of Thomas Hobbes of Malmesbury v.1. London: John Bohn.

Hoefer, C. (1996). The metaphysics of space-time substantivalism. Philosophy of Science, 93, 5-27.

Hudson, H. (2006). The metaphysics of hyperspace. Oxford: Oxford University Press.

Kant, I. (1965). Critique of pure reason (N. K. Smith, Trans.). New York: St. Martin's Press.

Kant, I. (1996). Critique of Practical Reason (T. Kingsmill, Trans.). New York: Abbott Prometheus Books.

Kuhlmann, M. (2006). Quantum field theory. Stanford Encyclopedia of Philosophy: http://plato. stanford.edu/entries/quantum-field-theory/.

Lewis, D. (1971). Counterparts of persons and their bodies. The Journal of Philosophy, 68, 203-211.

Lewis, D. (1986). On the plurality of worlds. Oxford: Basil Blackwell.

Locke, J. (1996). In K. P. Winkler (Ed.), An essay concerning human understanding. Indianapolis: Hackett Publishing.

Malcolm, N. (2002). Aspects of hobbes. Oxford: Oxford University Press.

Markosian, N. (2000). What are physical objects? Philosophy and Phenomenological Research, 61, 375395.

Maudlin, T. (1989). The essence of space-time. In Proceedings of the 1988 Biennial Meeting of the Philosophy of Science Association (Vol. 2, pp. 82-91).

Maudlin, T. (1993). Buckets of water and waves of space: Why space-time is probably a substance. Philosophy of Science, 60, 183-203.

Maudlin, T. (2007). Suggestions from Physics for Deep Metaphysics. In T. Maudlin (Ed.), The metaphysics within physics (pp. 78-103). Oxfor: Oxford University Press.

McDaniel, K. (2004). Modal realism without overlap. Australasian Journal of Philosophy, 82, 137-152.

Nerlich, G. (1994). The shape of space. Cambridge: Cambridge University Press.

Newton, I. (2004). De Gravitatione. In A. Janiak (Ed.), Isaac Newton: Philosophical writings. Cambridge: Cambridge University Press.

Norton, J. (2004). The hole argument, Stanford Encyclopedia of Philosophy: http://plato.stanford.edu/ entries/spacetime-holearg/.

Quine, W. V. O. (1981). Things and their place in theories. In W. V. Quine (Ed.), Theories and things (pp. 1-23). Cambridge: Harvard University Press .

Redhead, M. (1995). More ado about nothing. Foundations of Physics, 25, 123-137. 
Robinson, D. (1982). Re-identifying matter. The Philosophical Review, 91, 317-341.

Schaffer, J. (2007). Monism, Stanford Encyclopedia of Philosophy: http://plato.stanford.edu/entries/ monism/.

Schaffer, J. Monism: The priority of the whole, The Philosophical Review (forthcoming).

Sider, T. (2001). Four-dimensionalism: An ontology of persistence and time. Oxford: Oxford University Press.

Sklar, L. (1974). Space, time and spacetime. CA, USA: University of California Press.

Skow, B. (2005). Supersubstantivalism. In once upon a spacetime. Dissertation, New York University.

Spinoza, B. (1985). The collected works of Spinoza (E. Curley, Ed., Trans.). Princeton: Princeton University Press.

van Inwagen, P. (1981). The doctrine of arbitrary undetached parts. Pacific Philosophical Quarterly, 62, 13-37.

Weinberg, S. (1987). Towards the final laws of physics. In S. Weinberg \& R. Feynman (Eds.), Elementary particles and the laws of physics: The 1986 dirac memorial lectures (pp. 61-110). Cambridge: Cambridge University Press.

Wheeler, J. (1962). Geometrodynamics. New York: Academic Press.

Zeh, H. D. (2003). There is no first quantization. Physics Letters, A309, 329-334.

Zeyl, D. (2005). Plato's Timaeus, Stanford Encyclopedia of Philosophy: http://plato.stanford.edu/ entries/plato-timaeus/.

Zimmerman, D. (1996). Could extended objects be made out of simple parts? An argument for 'atomless gunk'. Philosophy and Phenomenological Research, 56, 1-29. 